\title{
Tinha um mas no início da pergunta
}

Camilo Rosa Silva*

UFPB

Recebido em: 19/06/2019

Aceito em: 08/11/2019

\begin{abstract}
Resumo: Este artigo enfoca usos do conector mas, considerado nas abordagens tradicionais como conjunção adversativa. Para tanto, recorre-se a fundamentos teóricos da Linguística Funcional Norte-Americana visando a descrever e analisar os usos do referido conector em amostras de entrevistas sociolinguísticas. Para a consecução desse propósito, são utilizados dados coletados no corpus O Linguajar do Sertão Paraibano (STEIN, 2013). O objetivo básico é identificar as nuanças ativadas nos contextos interrogativos nos quais o item introduz o gerenciamento do tópico discursivo. Nos referidos contextos, são acionadas subfunções discursivas diversas que em muito extrapolam as análises restritas ao valor semântico-gramatical do item.
\end{abstract}

Palavras-chave: Conjunção. Tópico. Mas.

Abstract: This paper focuses the connector "mas" considered in traditional approaches as oppositive conjunction. The theoretical foundations of North American Functional Linguistics are used to describe and analyze the uses of this connector in samples of sociolinguistic interviews. For this purpose, data collected in the corpus O Linguajar do Sertão Paraibano (STEIN, 2013) are used. The basic objective is to identify the particularities activated in the interrogative contexts in which the item introduces the management of the discursive topic. In these contexts, several discursive subfunctions are triggered which in much extrapolate the analyzes restricted to the semantic-grammatical value of the item.

Keywords: Conjunction. Topic. Mas.

Resumen: Esta investigación se centra el conector mas, tradicionalmente considerado un conjunción adversa. Para ello, se recurre a fundamentos teóricos de la Linguística Funcional para describir y analizar los usos del referido conector en muestras de entrevistas sociolinguísticas. Para la consecución de ese propósito, se utilizan datos recogidos en el corpus O Linguajar do Sertão Paraibano (STEIN, 2013). El objetivo básico es identificar los matices activados en los contextos interrogativos en los que el elemento introduce la gestión del tema discursivo. En estos contextos, se accionan subfunciones discursivas diversas que extrapolan los análisis restringidos al valor semântico e gramatical del ítem.

Palabras clave: Conjunción. Tema discursivo. Mas. 


\section{Contextualizando}

Em diversos estudos que utilizam dados de língua em uso no português do Brasil, o item linguístico mas, que traz seu sentido original de oposição tradicionalmente classificado como conjunção adversativa, destaca-se por sua produtividade, impondo-se como o prototípico de sua categoria.

Nessa perspectiva, conectores opositivos, dentre os quais se situam adversativos e concessivos, são formas linguísticas que relacionam informações semanticamente contrastivas, podendo expressar valores como: objeção, compensação, comparação, exclusão, inclusão, exclusividade, dentre outros. Essa relação, entretanto, nem sempre se estabelece linearmente, na superfície do texto, sendo, não raramente, acionada na dimensão discursivo-pragmática, realçando outras subfunções, como por exemplo, a de contraexpectativa. A concepção de “informação pragmática” ora aventada está relacionada ao evento de produção, à recepção e à interpretação contextual, influenciada pelos conhecimentos, saberes, crenças, suposições, sentimentos, pontos de vista, opinião, entre outros fatores intervenientes no processo de interação.

Tem-se, então, uma forte razão para investigar o funcionamento do mas e, em o fazendo, observa-se como sua polifuncionalidade instiga um processo de mudança por gramaticalização, exercendo papel relevante na gestão da topicalidade discursiva. Por gramaticalização, entende-se, ao longo deste texto, a mudança linguística que ocorre quando palavras e expressões percorrem contínuos funcionais, envolvendo principalmente a morfossintaxe e a semântica, e passam a assumir características de outras classes, distintas de sua função original. Ou seja, no interior da própria gramática da língua, ocorre uma movimentação que leva itens e expressões a migrarem para funções cada vez menos autônomas e por isso mais gramaticais. Como esse não é o foco da presente análise, a referência ao fenômeno será apenas en passant.

O item mas, conforme será demonstrado adiante, é bastante eficiente quando o objetivo do enunciador é controlar o fluxo temático, sendo acionado para diversas intervenções discursivas relacionadas a esse controle.

Ao se lançar o olhar sobre a abordagem das conjunções em materiais didáticos que circulam nas comunidades escolares, constata-se que as análises quase sempre se restringem à identificação da função gramatical, ou textualizadora, sendo esses itens 
caracterizados como responsáveis apenas por relacionar informações, abdicando-se de enxergar o arsenal discursivo-pragmático que envolve seus usos em contextos os mais diversos.

Pesquisas recentes têm se debruçado sobre o comportamento de algumas classes, com riqueza de detalhes, como se pode verificar em acervos de estudos funcionalistas sobre a gramaticalização de itens e de construções, especialmente, de dados do português brasileiro. Partindo dessa conjectura, este estudo vislumbra a conjunção, admitindo sua relativa condição de classe fechada, mas buscando expandir o olhar para um horizonte em que não haja fronteira rígida. Desse modo, a conjunção é inserida num domínio funcional em cujo interior itens tradicionalmente acomodados podem, a qualquer momento da história da língua, ver seu âmbito de prototipicidade ampliado pela inclusão de novas camadas.

Obviamente, é impossível estudar língua sem recorrer ao aporte da metalinguagem, independentemente da vertente teórica condutora do estudo. Isso significa que tomar a classificação tradicional, que mira pouco a descrição e mais a prescrição, é prática corriqueira até mesmo em trabalhos que se pretendam mais reflexivos. Há que se partir de algum lugar. Sempre existe uma referência precursora, mesmo que se vá tentar desconstruí-la ou reordená-la. Por esse motivo, procura-se não estigmatizar o uso do termo conjunção, que aqui será revezado com conectivo ou conector, sem que isso intente remeter a distinções relevantes.

A presente proposta pretende abordar o uso da conjunção como inerente a um domínio funcionalmente discursivo. Ela pertenceria a uma classe introdutora de direções interpretativas para as intenções dos usuários quando estes produzem enunciados ${ }^{1} \mathrm{em}$ situações comunicativas. Para dar conta do propósito da presente reflexão, fez-se preciso um novo recorte, posto que o conector mas, consagrado como prototípico de sua categoria - conjunção adversativa - ora cotejado em sua multidimensionalidade semântica, discursiva e pragmática, apresenta-se em contextos específicos de início de perguntas

\footnotetext{
${ }^{1}$ Entende-se enunciado como uma sequência linguística concreta, na qual está presente pelo menos um falante que produz linguagem verbal - real ou potencialmente direcionada a outrem - e que, portanto, está envolvido numa situação comunicativa. Nesse sentido, as condições de produção e de recepção são determinantes para a interpretação que Ihe será aplicada, considerando os recursos discursivos materializados linguisticamente.
} 
sugerindo uma ampliação - e ao mesmo tempo uma especialização - de seu campo funcional.

Assim, de olho nesse contexto específico de uso do mas, a análise em tela foca a descrição do comportamento do referido item em entrevistas que compõem o corpus $\mathrm{O}$ Linguajar do Sertão Paraibano (STEIN, 2013)², buscando apontar/demonstrar as nuanças manifestadas nos contextos em que, ao introduzir enunciados interrogativos, o item faz valer a função de sequenciador. A motivação para esse recorte vem da observação de que, em tais contextos, são acionadas subfunções discursivas nem sempre apontadas nas análises tradicionais, que limitam suas reflexões ao valor semântico-gramatical desse item ${ }^{3}$.

O ponto de vista a partir do qual os dados serão tratados é influenciado por uma perspectiva funcional que busca identificar prováveis especificidades identificadas nos usos assinalados. Dessa perspectiva, aciona-se a Linguística Funcional Norte-Americana, com sua concepção de gramática fluida, emergente, enfim, em permanente construção.

Pretende-se, portanto, descortinar um olhar teórico que possa ser produtivo no trabalho de descrição da língua enquanto fenômeno dinâmico e variável. Para isso, o texto está organizado em seções que, na sequência da exposição, pretendem: repercutir, panoramicamente, tratamentos destinados à conjunção mas nas perspectivas tradicional e funcional; apresentar os aportes teóricos da vertente denominada de Linguística Funcional Norte-Americana; e analisar dados de língua em uso nos quais o item mas exerce funções não-canônicas. A essas seções, somam-se esta contextualização introdutória e algumas considerações finais.

\section{Conjunção: o mas entre as perspectivas tradicional e funcional}

Nesta seção, apresentam-se, brevemente, algumas das lições tradicionais que têm reincidido sobre conceitos e formas das conjunções, além de discussões estabelecidas pela

2 O corpus Linguajar do Sertão Paraibano (STEIN et al., 2013) é constituído por entrevistas sociolinguísticas realizadas nas cidades da região geográfica denominada Sertão da Paraíba, atendendo os rigores metodológicos que caracterizam a abordagem da Sociolinguística Variacionista.

${ }^{3}$ Como a análise que ora se apresenta restringe-se ao comportamento funcional do item, caracterizando-se como qualitativa, não serão apresentados dados quantitativos, embora se possa advertir que são elevados seus índices de frequência nos contextos em tela. 
tentativa não tão antiga de melhor descrever o fenômeno da conexão e seus desdobramentos numa perspectiva funcional.

A conjunção é vista, no contingente das abordagens consideradas tradicionais, como uma classe fechada de palavras, de morfologia invariável, encarregada pela conexão entre orações ou segmentos nominais, responsabilizando-se pelo tipo de relação semântica que vai envolver as partes conectadas. Entretanto, numa perspectiva de gramática emergente, nos moldes formulados por Hopper (1987), há que se questionar essa maneira de enxergar a conjunção. Uma gama ampla de estudos que tomam essa classe como objeto aponta a constante inserção de novos itens, oriundos de outras classes, especialmente da dos advérbios, que são fornecedores de elementos conjuncionais à gramática das línguas.

Visitando um passado remoto, mas importante para entender a história da conjunção no português, sabe-se que, no latim popular, predominava a justaposição. Esse fato é apontado como causa da extinção dos itens conjuncionais naquela língua. Provavelmente, foi esse o contexto em que surgiu um uso inovador para o advérbio magis: o papel de conector adversativo. Nesse cenário, Barreto (2002) inclui, além do magis, as concessivas quamvis, etsi, licet, quanquam, que foram suprimidas, dando lugar a locuções com quod.

É sabido que o valor semântico de base do advérbio magis consistia em estabelecer comparações de quantidades e de qualidades, apresentando, ainda, valores secundários de inclusão de indivíduos num conjunto, funcionando, assim, como um advérbio predicativo intensificador. Segundo Castilho (2002), esse valor levou mas a atuar discursivamente, conectando turnos e unidades discursivas. Alvo de várias transformações metonímicas, o item se converteu em conjunção, passando, assim, a operar no nível gramatical. Para o autor, o uso conjuntivo do mas atesta a destituição de suas propriedades semânticas, enquanto advérbio de inclusão, ocorrendo uma perda de massa fonética, na evolução de magis a mas ou mesmo $/ \operatorname{majs}^{4} /$.

Bechara (2009) aponta uma atuação desse item unindo estruturas coordenadas, as quais comungam de idêntico nível sintático. Para o autor, as conjunções adversativas,

\footnotetext{
${ }^{4} \mathrm{Na}$ língua oral, mormente em contextos de baixa ou nenhuma formalidade, /m'ajs/é a pronúncia que prevalece no português do Brasil.
} 
subclasse a que pertence o mas, "enlaçam unidades apontando uma oposição entre elas". Ele afirma, ainda, que as adversativas por excelência são mas e porém, conjunções ratificadoras da oposição; além de senão, que marca a incompatibilidade. (BECHARA, 2009, p. 322). 5

A análise que Neves (2000) realiza sobre o item mas baseia-se em fatores tais como a natureza da relação, o modo da construção, e o valor semântico. A autora percebe, no funcionamento do item, características que talvez expliquem a predominância de uso entre os adversativos, especialmente, o eficiente estabelecimento de relações entre sintagmas, orações e enunciados.

Embora não seja habitual entre os autores considerados tradicionais evidenciar especificidades do funcionamento das conjunções, o mas, talvez pela sua polivalência exacerbada, foge a essa tendência. Cunha (1986), por exemplo, capta a presença de valores afetivos nos usos do item, chegando a defender que ele pode exprimir ideias de restrição, retificação, atenuação, compensação, adição e outros mais. O autor faz menção, ainda, a um traço desse elemento que tem estreita relação com a defesa de que o mas atua de modo relevante no gerenciamento do tópico: “é particularmente importante o emprego desta conjunção (assim como o de porém) para mudar a sequência de um assunto, geralmente com o fim de retomar o fio de enunciado anterior que ficara suspenso". (CUNHA, 1986, p. 538)

Assim, longe de restringir-se à oposição pura e simples, o mas difunde-se por searas discursivo-pragmáticas que acionam significados outros, extrapolando seu papel de conectivo gramatical, como será demonstrado adiante.

Pelo exposto, percebe-se que a diacronia do mas é documentalmente recuperável do latim até os dias atuais, pelo menos, em se tratando de seu papel semântico-gramatical. A tradição gramatical aponta essa conjunção como a que melhor caracteriza a relação da adversidade na língua portuguesa, valor que também é destacado em trabalhos funcionalistas. Em pesquisa realizada em corpus de língua escrita, constituído por editoriais jornalísticos, Silva (2007), por exemplo, observa usos diversos do item na

\footnotetext{
${ }^{5}$ Silva (2007) assinala que pesquisas em corpora de português falado no Brasil, no final do século XX e início do XXI, corroboram os usos do mas como item adversativo de maior índice de frequência, e atestam o desuso categórico do porém, a despeito dos grupos de informantes serem representativos dos mais diversificados estratos de escolaridade, idade e sexo/gênero.
} 
emergência de sutilezas funcionais variadas que, no entanto, não chegam a anular categoricamente sua natureza opositiva. Mas será que, com o subsídio das correntes funcionalistas já referidas, (não) seria possível refinar a descrição?

\section{Um olhar funcional sobre o mas}

De modo geral, um estudo linguístico pode se assumir funcionalista - tomando o polo formalista como contraponto - quando ele considera a organização das línguas naturais a partir das funções comunicativas a que tais línguas servem (NEVES, 2003). Assim, um pressuposto como o de que a forma é determinada/influenciada pela função, ou seja, o componente morfossintático está a serviço da função comunicativa, é compartilhado pelas diversas correntes teóricas funcionais.

A vertente dos estudos funcionalistas da linguagem defende uma concepção de língua como estrutura maleável, dinâmica e permanentemente sujeita às pressões co(n)textuais. Nela, a gramática é indissociável do discurso, no qual atuam entrelaçados os componentes sintático, semântico e pragmático, tidos como elementos essenciais ao alicerce de análises balizadas pelo uso. O ponto de partida é a relação forma-função, no caso deste trabalho, circunscrita ao item linguístico mas e sua atuação num contexto estrutural específico: a abertura de enunciados interrogativos.

Portanto, numa concepção de linguagem como atividade sociocultural que serve a funções cognitivas e comunicativas (GIVÓN, 1995), observa-se a forma que materializa um determinado conector visando desnudar sua função para além dos contornos sintático e semântico. Nesse ambiente teórico, a abordagem assumida observa dados de língua em situação de uso e, ao investir na relevância do contexto, contempla, em alguma medida, a pragmatização dos sentidos.

Alguns estudos funcionalistas defendem que a natureza sistemática do desenvolvimento de processos mentais e comunicativos que governam o uso da língua determina a natureza sistemática da gramática. Nesses termos, a gramaticalização se materializa na interação falante/ouvinte por um viés não somente estrutural e discursivo, mas também cognitivo (BYBEE, PERKINS E PAGLIUCA, 1994).

Hopper e Traugott (2003, p. 2) defendem a relevância e interferência do contexto como ativador específico da mudança, o que sugere ser possível propor um mapeamento 
dos contextos de uso e distinguir aqueles mais favorecedores de determinadas inovações nos usos gramaticais.

Considerando o conector ora estudado, é oportuno destacar o quanto as especificidades contextuais interferem nas escolhas dos falantes, anotando-se, também, a tendência à especialização que influencia essas escolhas e consolida a ativação de subfunções específicas.

Um dos papéis discursivos presente nos usos analisados está diretamente relacionado ao gerenciamento da topicalidade. Para Givón (1992), a materialização do tópico depende de um conjunto de instruções do processo mental que causam operações específicas na mente do interlocutor. Destarte, os sinais gramaticais que codificam o tópico representam o esforço do emissor para embasar a informação na perspectiva do receptor.

Ainda segundo Givón (1992), as propriedades pragmático-discursivas da topicalidade são a previsibilidade referencial e a relevância temática. Elas representam os correlatos cognitivos que abrigam a busca pelo referente na representação mental do texto e a ativação da atenção do receptor. Para o autor, a topicalidade é mobilizada pela cognição. Assim, os sinais gramaticais usados no texto para codificar o tópico visam a causar operações específicas e atendem ao desejo do emissor de adensar a informação com o máximo de elementos que viabilizem a compreensão por parte do interlocutor. ${ }^{6}$

Com uma contribuição bastante relevante para os estudos linguísticos, numa perspectiva textual-interativa, Jubran (2006, p. 90) defende que o tópico consiste num processo responsável pela construção da conversação, vista como um complexo de fatores contextuais, "entre os quais as circunstâncias em que ocorre o intercâmbio verbal, o grau de conhecimento recíproco dos interlocutores, os conhecimentos partilhados entre eles, sua visão de mundo, o background de cada um em relação ao que falam”.7

\footnotetext{
${ }^{6}$ Givón (2001) traz uma longa discussão sobre as categorias sintáticas codificadoras do tópico, que aqui não será retomada porque ela extrapolaria os limites da análise e a pretensão de observar o comportamento do mas em contextos nos quais ele aciona o tópico discursivo, na acepção de assunto.

7 Jubran (2006) apresenta uma tipologia em que divide as formas de linearização entre segmentos mínimos: (i) continuidade tópica; (ii) descontinuidade tópica; (iii) outras formas de linearização tópica. A autora refina essa classificação, desdobrando a "descontinuidade" em ruptura, cisão (inserção e alternância) e expansão; e as "outras formas" em transição, superposição e movimento.
} 
Via de regra, o tópico tem sido analisado a partir de duas perspectivas: i) sintática: pode se materializar lexical ou pronominalmente, em posição estrutural quase sempre à esquerda do comentário/predicado ou ii) discursiva: quando assinala a posição do falante/emissor acerca de algumas pressuposições que ele imagina serem de competência do ouvinte/receptor.

Isso posto, o que está em evidência na presente reflexão é o valor discursivo do tópico que é manipulado nos usos do mas - cujo teor originalmente opositivo não se explicita na textualidade linguística - além da percepção de que a informação topicalizada encontra-se no domínio contextual.

O tópico está sendo aqui entendido como uma atividade construída cooperativamente, na qual há convergência entre aquilo que o falante enuncia e o que é decodificado e interpretado pelo interlocutor, ou seja, o conteúdo temático é identificado por ambos. Ocorre, então, nos eventos interacionais, algum grau de correspondência mental entre os interlocutores, uma vez que na organização conversacional, os participantes têm, pelo menos, o mínimo de conhecimento sobre o assunto, como também, domínio das estratégias que acionam a mudança, a digressão, a retomada, etc. (Cf. BROWN \& YULE, 1983).

Itens linguísticos que orientam o discurso e direcionam a interpretação, sem que refiram quaisquer dados do mundo, têm sido chamados de marcadores discursivos. É o que parece acontecer com o mas acionado na tomada de turno das entrevistas sociolinguísticas apresentadas adiante. Como esses elementos funcionam não na organização sintagmática do enunciado, mas num domínio discursivo que parece ativar forças pragmáticas, sua classificação vai ficar na dependência da concepção de gramática com a qual se está lidando.

De olho nos usos do mas interrogativo, a análise ora proposta refletirá sobre essas questões.

\section{Análise funcional dos dados}

Conforme anotado em passagens anteriores, nas gramáticas tradicionais, predomina um tratamento que define o mas como conjunção coordenativa adversativa. Entretanto, não é raro que sua atuação extrapole a adversidade, desempenhando outras 
subfunções em que seu papel contrastivo é atenuado ou em que se sobrepõem outros valores discursivos.

Na tentativa de realizar uma descrição mais ampla, realçam-se alguns cenários em que se pode vislumbrar especificidades nos usos do conector. Daí seria possível cogitar as regularidades que compõem a emergência de um determinado microdomínio funcional no qual ele atua.

Além de demarcar o contraste semântico interoracional, percebe-se a atuação do mas com outras funcionalidades, dentre as quais destacam-se duas, assinalando-se a inter-relação que as envolve: i) na manifestação da quebra de expectativa que se dá não na linearidade sequencial das informações, mas sim, cooptando inferências e pressupostos; ii) na atividade comunicativa de tomada de turno, atuando na topicalidade, quando aciona subfunções discursivas.

Dessa maneira, o escopo estrutural que o item abrange é, a princípio, dependente de seu teor semântico ativador da função gramatical, mas seu papel discursivo vai além das relações textuais, acionando funções discursivo-pragmáticas.

Diferentemente do que costuma ser prática nas pesquisas que se utilizam de material coletado em entrevistas sociolinguísticas, quando se descarta a intervenção do entrevistador por considerá-la um uso planejado e automonitorado, a presente análise se interessa também por esse material, uma vez que, nesses eventos, na tomada de turno por parte desse usuário, é quantitativamente elevada a frequência de uso do mas introduzindo enunciados interrogativos. Desse modo, interessam todas as aberturas de turno, independentemente de serem do informante ou do entrevistador. Por essa decisão, pretende-se deixar claro que os textos analisados são produto da interação entre ambos os interlocutores, o que influencia diretamente no gerenciamento tópico compartilhado.

Por esse ponto de vista, o mas, quando usado em contexto de tomada de turno, introduz perguntas que envolvem o tópico discursivo de diferentes maneiras: recupera-o, mantém-no, reorienta-o, desativa-o. O entrevistador se faz valer de sua habilidade discursiva para aprofundar, detalhar, questionar, contrapor, investindo em atitudes linguísticas mais - ou menos - eficazes, conforme o (des)favorecimento do contexto.

Observe-se como esse comportamento se revela nos dados em estudo: 
(1) I: Sempre quando a gente se encontra, apesar da gente também ser colega na sala de aula... é pra falar nos estudos ou pra conversar alguma coisa, assim.

E: Mas aí, o pessoal vai muito pra essa discoteca? Não os teus amigos, outras pessoas?

I: Vai, vai, e lá é bom, eu já fui. Ahn, assim...

(LSP; Inf. 1)

A entrevista se encontra num ponto em que o informante (I) é questionado sobre uma casa noturna que há na cidade. No trecho em evidência, ele usa o controle do turno para uma informação parentética que, de certa forma, desvia o cerne do assunto proposto pelo entrevistador (E), cuja curiosidade central recaía sobre que classe social da cidade frequentava o referido ambiente. Ao assumir o turno de fala, (E) retorna para o tema específico: a frequência da discoteca pela população da cidade. Desse modo, (E) realiza uma intervenção discursiva que visa a não permitir que (I) perca o tópico discursivo de vista e deixe suas questões sem as respostas esperadas. Há uma busca tanto por recuperação do tópico como por aprofundamento informacional.

O mas que introduz a fala de (E), em (1), não está ligando ou relacionando orações, daí a sobreposição do traço sequenciador. Não obstante, ocorre a persistência (cf. HOPPER, 1991) do teor adversativo, que emerge não da relação entre as informações prévias e as posteriores, no plano da superfície do texto, e sim de um processo inferencial, uma vez que (E) intenta sinalizar para (I) que este não atendeu às expectativas em relação às informações mais relevantes desejadas.

No caso do recorte (2), a seguir, o que ocorre é mesmo mudança de tópico:

(2) I: Eu queria ir, mas em relação à cidade eu queri/ quero morar aqui. Pouco aqui a gen/ a gente fala muito em seca, por quê? Porque aqui chove pouco, mas em relação a... abastecer a cidade [...] a gente nem se preocupa porque aqui disponibiliza de muita água... que tem muita água.

E: Mas, assim, você já ouviu falar dos seus pais como era antigamente, aqui, // você sabe?

Revista Investigações, Recife, v. 32, n. 2, p. 353 - 369, Dezembro/2019 
A conversação se mantém em torno da opinião de (I) sobre a situação hídrica da cidade que se localiza em área onde a incidência de secas é recorrente. (I) relata sua visão acerca do tema, mas é interrompido por (E), que impõe um novo direcionamento temático à conversa: como era a cidade em tempos passados.

A atuação do mas permite uma leitura identificadora da persistência de seus traços conectivos, uma vez que, mesmo fugindo ao contexto de fronteira oracional e atuando discursivamente, ele não deixa de ativar o fluxo informacional. Assim, até quando ocorre mudança de tópico, os elos coesivos inerentes à elocução dialogada, característica do gênero textual em tela, são mantidos. Entretanto, o que parece ser mais relevante é o fato de o conector ser usado em contexto interrogativo e destituir-se de sua funcionalidade mais prototípica que é a ativação de ideias opositivas.

Nas ocorrências (3) e (4), a seguir, (E) realiza intervenção visando à manutenção do tópico:

(3) E: Qual a diferença entre a Catolé do passado e a Catolé de agora, assim, que mais lhe impressiona? Qual a diferença?

I: O setor industrial.

E: Por quê?

I: Porque Catolé, hoje, já tem ganhado um campo muito grande na parte industrial, né? Nós já dispomos de, de, de várias indústrias. Nossa cidade já tem garantia de empregos, né... pra muitos cidadãos catoleense. [...] Isso é uma das coisas que foi bom pra cidade, que eu vejo com muito orgulho.

E: Ahn. Mas foi bom, assim, por quê?

I: Geração de empregos, né... que é um dos pontos fundamentais. E também o nome da cidade vai se evoluindo a cada vez mais. [...].

(LSF, Inf. 1)

Nesse contexto, a investida de (E) busca instigar seu informante a elaborar mais o tema em desenvolvimento e alongar o relato. Sua intervenção, portanto, objetiva manter Revista Investigações, Recife, v. 32, n. 2, p. 353 - 369, Dezembro/2019 
o tópico, estimulando (I) a fornecer mais informações sobre a cidade, que é o assunto desenvolvido. No gênero entrevista, esse recurso mostra-se recorrente posto que o entrevistador procura controlar, além do tempo de duração do evento, o contingente informacional que vêm à tona. Na entrevista sociolinguística, isso também ocorre, embora, nesse caso, o interesse real não seja a qualidade da informação propriamente dita, mas fazer com que o informante produza o maior volume possível de texto, mantendo uma pretensa naturalidade na elocução.

Segundo Givón (1990), na produção discursiva, nenhuma sentença é totalmente independente do contexto oracional imediato. Nos dados analisados, certamente, essa dependência se efetiva em maior ou menor grau, podendo ser atenuada por pressupostos e inferências. De fato, em contextos de oralidade, esses fatores são ainda mais incidentais, especialmente, em enunciações dialogadas. Assim, é possível que o contexto contribua com implicaturas e influencie as escolhas linguísticas que demarcam intenções do usuário.

Em (4), num contexto semelhante ao anteriormente apresentado, o mas introduz uma intervenção de (E), no propósito de fazer com que (I) alongue seu relato em torno do assunto em tela, que seria uma maneira de manter e aprofundar o tópico:

(4) E: Eu queria saber, né, você é humorista, né, tem essa, essa veia cômica... aí, eu queria que você contasse aqui pra gente como é, aí, a vida de humorista, né, o que é que você tem pra falar, assim... no geral da s/ da vida de um humorista.

I: É bom. Uma vida boa, a gente brinca, né, sempre tem que tar com o espírito brincalhão. Mas, que as dificuldades existe. Tudo que você vai fazer na vida, você encontra atalhos, ahn, problemas, mas, a, o importante é a gente erguer a cabeça, tocar a vida em frente. [...]

E: Mas, e aí, como é que são as dificuldades, assim, que você encontrou?

I: Olha, as dificuldades, não é nem tanto o preconceito, isso existe, né. Mas, eu, graças a Deus, ahn, estou tendo uma aceitação muito grande onde eu vou.

Revista Investigações, Recife, v. 32, n. 2, p. 353 - 369, Dezembro/2019 
Nas ocorrências (3) e (4), a presença dos advérbios interrogativos deixa ainda mais marcada, gramaticalmente, a formulação da pergunta e evidencia a acomodação do mas ao contexto, posto que sua presença não parece causar qualquer estranhamento aos interlocutores.

Esse papel de interveniente no tópico, aqui ativado pelo mas interrogativo, pode estar relacionado, geralmente, tanto à digressão quanto à progressão temática - que é o que ocorre nos dois dados - de modo a que se mantenha a coerência global. No anseio de controlar os rumos da conversação, o entrevistador intervém, por vezes impositivamente, na tentativa de fazer o informante desenvolver com maior amplitude o tema - porque a ele interessa quantidade de texto - e, por isso, interpela-o sobre particularidades inerentes ao tópico.

Além disso, (E) pode entender que (I) detém conhecimentos para desenvolver mais profusamente o assunto. Assim, (E) pode interferir visando à retomada do tema negligenciado, uma vez que, na sua visão, (I) não atingiu satisfatoriamente a essência do tema pontuado na pergunta.

Também, é possível que (I) dê por esgotado o tema, como demonstrado em (5), a seguir:

(5) E: E quando não tinha essa ajuda, assim, do exército com, com os carros-pipa... como é que vocês faziam?

I: era... consumindo a que tinha mesmo. Água de... muito ruim e... adoecia até gente. Que essa água salobra, se cê be/... consumir muito ela... adoece da uretra. Adoece d/ muitos problema. E aqui, s/ água boa se... tirando do inverno, pegar na cisterna... só se as pipa trouxer, se não trouxer aí... É comprar uma pipa lá quem tem o dinheiro, quem não tem... [...]

E: Aí, no caso, quando pega um ano, assim hoje em dia que, igual o senhor tá falando...tem, ahn, os carros-pipa, né.

I: É. 
E: Mas de primeiro, quando não tinha, que ficava um ano, assim... de estio grande... como é que vocês faziam pra se virar?

(LSP; Inf. 04)

A resposta monossilábica de (I) é indício de que o assunto lhe parece exaurido, enquanto a tomada de turno por parte de (E) revela sua intenção de evidenciar detalhes que poderiam levar a uma maior exploração do tópico.

Givón ([1979], 2013) defende que as perguntas são fenômenos pressuposicionais. Isso não remove delas o poder de retomar conhecimento codificado, mas aponta sua capacidade de ativar pressupostos. $\mathrm{O}$ autor entende que a topicalidade também constitui um fenômeno pressuposicional. Assim, a mudança de tópico estaria relacionada à hipótese do falante em função da habilidade do ouvinte no que se refere à identificação dos argumentos. Por esse ângulo, os eventos enunciativos em formato de diálogos são terreno fértil para a ativação da topicalidade pela via do conhecimento (supostamente) partilhado. Os dados desta pesquisa parecem ratificar essas assertivas.

É possível que o valor semântico do item sob investigação, em contextos como os expostos nos excertos, mantenha-se opositivo, numa gradiência de maior ou menor potencial, até chegar à completa destituição desse valor. Entretanto, o relevante é que ele pode conduzir, em primeiro plano, um recurso mais salientemente sequenciador do que contrastivo.

Os dados, acima de qualquer contestação, expõem uma polifuncionalidade do item que demanda um olhar mais atento para sua análise e classificação do que simplesmente o que o limita à classe das conjunções adversativas. Silva (2005) organiza um panorama funcional no qual o mas revela sua extensão funcional em usos de língua escrita, chegando o autor a listar 26 subfunções discursivo-textuais do item em editoriais jornalísticos.

Pela análise aqui exposta, percebe-se que o comportamento do mas em contextos interrogativos revela uma alteração no seu papel original de conector gramatical que demarca a fronteira entre informações contrapostas. Nos usos ora realçados, ativa-se um papel predominantemente discursivo e mobilizam-se elementos pragmáticos compartilhados entre os interlocutores. Essa seria uma manifestação da gramaticalização, vista como processo que leva itens a atuarem em funções cada vez mais subjetivas, se 
considerarmos o discurso e a pragmática como domínios indissociáveis da gramática da língua.

\section{Considerações finais}

A diversidade de valores observados na utilização do mas em contextos específicos de interrogação, conforme exposto neste trabalho, aponta a ativação dos recursos pragmaticamente interpretativos que são acionados nos eventos interacionais.

Os dados explicitam que o enunciado interrogativo constitui, nas entrevistas, um recurso eficiente no gerenciamento do tópico e que a presença do mas nesses contextos ressalta seu valor discursivo, ativador de implicaturas que demarcam uma atuação pragmática, contextualmente localizada. Afinal, é impossível separar a estrutura do texto do contexto em que ele é produzido e interpretado.

A presente discussão evidencia que o papel do conetor em contextos interrogativos de tomada de turno faz emergir um vigor discursivo que atua diretamente no controle do tópico e introduz, entre outros fatores, tanto intenção de manter como a de mudar de assunto. Não se pode pensar que o mas, sozinho, seja responsável por essa função; entretanto, também não se pode deixar de sublinhar que ele é produtivo e eficiente na introdução desses segmentos e parece absolutamente acomodado ao conhecimento linguístico e discursivo-pragmático partilhado pelos usuários envolvidos em situações várias de uso da língua.

\section{Referências}

BARRETO, T. M. M. Observações sobre as conjunções no século XVI. In MATTOS E SILVA, R. V.; MACHADO FILHO, A. V. L. (Org.). O Português quinhentista: estudos lingüísticos. Salvador: Edufba/UEFS, 2002, v. 1, p. 161-193.

BECHARA, E. Moderna gramática portuguesa. 37. ed. rev., ampl. e atual. Rio de Janeiro: Nova Fronteira, 2009.

BYBEE, J.; PERKINS, R.; PAGLIUCA, W. The evolution of grammar: tense, aspect, and modality in the languages of the world. Chicago: Chicago Press, 1994.

BROWN, G; YULE, G. Discourse analysis. Cambridge: Cambridge University Press, 1983.

CASTILHO, A. T. A língua falada no ensino de português. 4. ed. São Paulo: Contexto, 2002. 
CASTILHO, A. T. Nova gramática do português brasileiro. São Paulo: Contexto, 2012.

CUNHA, C. Gramática da língua portuguesa. 11. ed. Rio de Janeiro: Fename, 1986.

GIVÓN, T. On understanding grammar. New York: Academic Press, 1979.

GIVÓN, T. Syntax: a functional-typological introduction. Amsterdam: John Benjamins, v.2, 1990.

GIVÓN, T. The grammar of referential coherence as mental processing instructions. Linguistics, Berlin, 1992. p. 5-55.

GIVÓN, T. Functionalism and grammar. Amsterdam: John Benjamins, 1995.

GIVÓN, T. Syntax. V. I. Amsterdam/Philadelphia: John Benjamins Publishing Company. 2001.

HOPPER, P. Emergent Grammar. Proceedings of the Thirteenth Annual Meeting of the Berkeley Linguistics Society, 1987, p. 139-157

HOPPER, P. On some principles of grammaticalization. In: TRAUGOTT, E \& HEINE, B. Approaches to grammaticalization, V.1, Amsterdan: Benjamins, 1991, p. 17-37.

HOPPER, P.; TRAUGOTT, E. Grammaticalization. Cambridge: Cambridge University Press, 2003. JUBRAN, C. A. S. Tópico discursivo. In Célia Jubran e Ingedore Kock (orgs.). Gramática do português culto falado. Campinas: Editora da Unicamp, 2006. P. 89-132.

NEVES, M. H. M. Que gramática estudar na escola? Norma e uso na língua portuguesa. São Paulo: Contexto, 2003.

NEVES, M. H. M. Gramática de usos do português. São Paulo: UNESP, 2000.

STEIN, C. C. O Linguajar do sertão paraibano. (Corpora urbano e rural). João Pessoa, EDUFPB, 2013 .

SILVA, C. R. Por uma gramática funcional. In SILVA, C. R. (org.) Ensino de português: demandas teóricas e práticas. João Pessoa: Ideia, 2007.

SILVA, C. R. Mas tem um porém...: mapeamento funcionalista dos conectores de oposição em editoriais jornalísticos. Tese de Doutorado (Doutorado em Letras). João Pessoa: UFPB, 2005. TRAUGOTT, E. C. Grammaticalization and mechanisms of change. In Bernd Heine and Heiko Narrog (eds.). The Oxford handbooks of grammaticalization. Oxford handbooks online. 2011.

\footnotetext{
* Doutor em Letras pela UFPB com Pós-Doutorado em Letras na UNIFESP. Professor do Programa de Pós-Graduação em Linguística da UFPB. Líder do Grupo de Investigações Funcionalistas (GIF).
} 